\title{
IMMUNOHISTOCHEMISTRY IN THE DIFFE- RENTIAL DIAGNOSIS OF SOLITARY THYROID NODULE.
}

\author{
By \\ Maha M Amin, MD and Dina A El-Tantawy, MD
}

\author{
From \\ Pathology Department, Faculty of Medicine, \\ Mansoura University, Egypt.
}

\begin{abstract}
Evaluation of solitary thyroid nodule is the most common thyroid problem; the prevalence varies according to the method of screening used. Solitary thyroid nodule can be caused by any of the thyroid diseases; the majority is benign. Lesions characterized by a follicular growth pattern constitute the most common type encountered by pathologists. The vast majority of such lesions do not pose difficulties for histopathological interpretation. A subset of these tumors, however, can represent a serious challenge for diagnosis, management \& fall under the "indeterminate" category. Thyroid tumors with follicular growth pattern include a broad range of lesions that range from benign, hyperplastic nodules to
\end{abstract}

follicular adenoma and follicular carcinoma. In addition, other types of tumors with follicular growth pattern belonging to separate diagnostic categories, including the follicular variant of papillary carcinoma, atypical adenomas, Hy̌rthle cell tumor \& medullary carcinoma can be also encountered. The histologic features used for distinguishing these conditions can be sometimes subtle \& subjective.

The present study was performed on 77 excision specimens of solitary thyroid nodules with predominate follicular architecture. Immunohistochemical stains were done for selected cases for high molecular weight cytokeratin, chromogranin A, S-100 \& factor VIII. 
CONCLUSION : Most thyroid tumors with follicular architecture are diagnosed by morphology alone; however, immunohistochemistry can be used to differentiate between problematic cases exhibiting follicular pattern \& to detect true vascular invasion in follicular carcinoma.

\section{INTRODUCTION}

The most common thyroid problem is the evaluation of the patient with a single thyroid nodule; which are rare in children, their frequency increases in each decade \& more common in females than males (1). True solitary nodules occur in 0.22 $1.35 \%$ of the pediatric population \& need close attention because of increased frequency of malignancy \& more aggressive behavior than adults $(4 \%)^{(2)}$. The majorities of these nodules are benign and only $8 \%$ to $17 \%$ of nodules removed are proved to be malignant $(3)$.

Factors that increase the risk of malignancy includes; extremes of age, the incidence of carcinoma is higher in men (1), head and neck radiation especially in young age, family history of thyroid cancer, familial polyVol. 40, No. 1 \& 2 Jan., \& April, 2009 posis \& Autoimmune thyroiditis (4).

Solitary thyroid nodules may be neoplastic or non-neoplastic; the nonneoplastic nodules include cyst, multinodular goiter, prominent area of thyroiditis and glandular hyperplasia. The neoplastic nodules include adenoma and thyroid cancer ${ }^{(5)}$. The majority of thyroid neoplasms are primary and epithelial including both adenoma and carcinoma (6). However, tumors with follicular pattern often show diagnostic dilemma. Differential diagnosis includes; dominant nodule of nodular hyperplasia, follicular adenoma, follicular carcinoma, follicular variant of papillary carcinoma, insular carcinoma \& Medullary carcinoma $(6,7)$.

Follicular adenoma is the most common thyroid neoplasm. Follicular carcinoma, on the other hand, is rare and its identification depends mainly on the presence of capsular or vascular invasion which needs thorough pathological examination $(7,8$ \& 9$)$.

Papillary carcinoma is the most common thyroid cancer, and is common incidental finding in thyroid glands removed for other reasons. 
Multicentricity is a common feature of papillary carcinoma; however, it may present as solitary nodule. The diagnosis of papillary carcinoma depends on the presence of nuclear features rather than a papillary formation (10). The immunohistochemical profile of papillary carcinoma is different from that of normal follicles, especially positivity to HMW CK (11).

Medullary thyroid cancer and anaplastic or undifferentiated carcinomas are much more rare (3). The frequency of carcinoma in nodular goiter is about $25-60 \%$ of that in solitary nodules. The exception to this may be cases of multinodular goiter with a dominant nodule. They are reported to have $5 \%$ carcinomas. Thus, it must be evaluated as if it were a single nodule (12).

\section{MATERIAL \& METHOD}

The present study is performed on 77 excision specimens from solitary thyroid nodule cases with follicular architecture. All were received from Mansoura University Hospital and Mansoura Oncology Center.

Routine hematoxylin and eosin
(H\&E) were used for morphologic diagnosis. Classification into benign and malignant tumors was done according to that mentioned by (13).

Cases were classified into benign (which included both neoplastic and non neoplastic) and malignant; and all the neoplastic cases were classified based on the histogenetic origin of the tumor. Immunohistochemistry was applied for selected problematic cases, and for the delineation of some details as vascular invasion.

Antibodies required:

Pre-diluted, Monoclonal mouse high molecular weight (DAKO code No. M0630); diluted 1:50, Polyclonal rabbit anti-cow S-100 antibody (DAKO code No. Z0311), Monoclonal mouse anti-human chromogranin $A$ (DAKO code No. U 7030) \& Polyclonal rabbit anti-human factor VIII (DAKO code No. N1505).

Statistical analysis of data was done by using Excel program and SPSS program (statistical package of social science). Chi- square test and ANOVA test were used. $P$ is significant if $<0.05$.

MANSOURA MEDICAL JOURNAL 


\section{RESULTS}

In our study, benign lesions were about $71.43 \%$ of total \& malignant lesions were $28.57 \%$ of the total cases. The commonest cause of solitary nodule was the goitrous nodule $(35.06 \%)$ of total. The commonest neoplasm was follicular adenoma $(32.47 \%)$ of total. The commonest malignant tumor was papillary carcinoma (15.58\%) of total. Table (1)

As regard age distribution, the age was between $15-80$ years. The percent of malignancy was higher in the older age group, reaching more than $50 \%$ above the age of 60 year. Table (2)

Table (3) demonstrates female predilection for both benign and malignant cases. Total female to male ratio was 2.5: 1 .

Table (4) shows that both benign and malignant cases were more common on the right side $(49.4 \%$ of the total); the left side $(44.2 \%)$; the isthmus contained $6.4 \%$ of the total.

Results of the immunostains used for selected cases (Table (5):

Nineteen cases required immunostaining for definitive diagnosis. S-
100 and HMWK were helpful in the diagnosis of nodules with borderline nuclear features of papillary carcinoma; Chromogranin was used to help diagnosis of medullary carcinoma and finally factor VIII to differentiate between the endothelial hyperplasia and the true vascular invasion.

The number of papillary carcinoma in this study was 12 cases (about $15.58 \%$ of all cases) and they represented the highest incidence in the malignant cases (Table 1). There were eight cases with questionable focal clearing and grooving and all had follicular pattern. Three of them were diagnosed by $\mathrm{S} 100$ and HMWK as papillary carcinoma (fig. 1 \&2) and five cases showed no reactivity to $S$ 100 or HMWK and confirmed to be of hyperplastic nature.

The number of medullary carcinoma cases was two cases $(3.9 \%)$ of the malignant tumors. They showed positive immunostaining for chromogranin A (fig. 4).

There were four cases of follicular carcinoma $(5.19 \%$ of the cases) \& two cases of Hurthle cell carcinoma (2.6 \% of cases). They showed mitoses and definite vascular 
and capsular invasion.

Immunostaining for factor VIII was done in one case of follicular carcino- $\mathrm{ma}$ in which vascular invasion was suspected to differentiate between the endothelial hyperplasia and the true vascular invasion (figure 6).

Table (1) : Total number of solitary thyroid nodule cases with follicular pattern and their histological diagnosis:

\begin{tabular}{|l|c|c|}
\hline Histological diagnosis & No. & $\%$ of total \\
\hline non neoplastic follicular lesions: & 27 & $35.06 \%$ \\
\hline Goiterous nodule (GN) & & \\
\hline Benign neoplastic follicular lesions: & 25 & $32.47 \%$ \\
\hline 1-Follicular adenoma (FA) & 2 & $2.60 \%$ \\
2-Hürthle cell adenoma (HA) & 1 & $1.30 \%$ \\
3-Atypical adenoma (AA) & 28 & $36.37 \%$ \\
\hline Total benign neoplastic cases & 55 & $\mathbf{7 1 . 4 3 \%}$ \\
\hline Total benign cases & 12 & $15.58 \%$ \\
\hline Malignant lesions with follicular pattern: & 4 & $5.19 \%$ \\
\hline 1-Papillary carcinoma (PC) & 1 & $1.30 \%$ \\
2-Follicular carcinoma (FC) & 2 & $2.60 \%$ \\
3- Insular carcinoma (IC) & 2 & $3.90 \%$ \\
4- Hürthle cell carcinoma (HC) & & \\
5- Medullary carcinoma (MC) & 22 & $\mathbf{2 8 . 5 7 \%}$ \\
\hline Total No. of malignant cases & 77 & $\mathbf{1 0 0 \%}$ \\
\hline Total cases & & \\
\hline
\end{tabular}

Table (2): Age distribution in the three categories of diagnosis:

\begin{tabular}{|l|c|c|c|c|c|}
\hline $\begin{array}{l}\text { Histological } \\
\text { diagnosis }\end{array}$ & No. & Range & Mean & Median & S.D. \\
\hline Non-neoplastic & 27 & $15-60$ & 36.74 & 37.00 & 11.04 \\
\hline Benign neoplastic & 28 & $19-67$ & 40.70 & 40.00 & 12.20 \\
\hline Malignant & 22 & $18-80$ & 46.04 & 45.00 & 16.51 \\
\hline Total & 77 & $15-80$ & 40.69 & 40.00 & 13.70 \\
\hline
\end{tabular}


Table (3) : Gender distribution in the three categories of diagnosis:

\begin{tabular}{|l|c|c|c|c|c|c|}
\hline \multirow{2}{*}{$\begin{array}{l}\text { Histological } \\
\text { diagnosis }\end{array}$} & \multirow{2}{*}{ No. } & \multicolumn{2}{|c|}{ Female } & \multicolumn{2}{|c|}{ Male } & female: \\
\cline { 3 - 6 } & & No. & \% of group & No. & \% of group & Male \\
\hline Non-neoplastic & 27 & 20 & $74.1 \%$ & 7 & $25.9 \%$ & $2.9: 1$ \\
\hline Benign neoplastic & 28 & 21 & $75.0 \%$ & 7 & $25.0 \%$ & $3: 1$ \\
\hline Malignant & 22 & 14 & $63.6 \%$ & 8 & $36.4 \%$ & $1.8: 1$ \\
\hline Total & 77 & 55 & $71.4 \%$ & 22 & $28.6 \%$ & $2.5: 1$ \\
\hline
\end{tabular}

Table (4) : Site distribution of both benign and malignant categories:

\begin{tabular}{|l|c|c|c|c|c|c|c|}
\hline \multirow{2}{*}{ Type } & \multirow{2}{*}{ No. } & \multicolumn{2}{|c|}{ Right side } & \multicolumn{2}{c|}{ Left side } & \multicolumn{2}{c|}{ Isthmus } \\
\cline { 3 - 8 } & & No & $\%$ & No & $\%$ & No & $\%$ \\
\hline Non-neoplastic & 27 & 13 & $16.9 \%$ & 12 & $15.6 \%$ & 2 & $2.6 \%$ \\
\hline Benign neoplastic & 28 & 14 & $18.2 \%$ & 12 & $15.6 \%$ & 2 & $2.6 \%$ \\
\hline Malignant & 22 & 11 & $14.3 \%$ & 10 & $13.0 \%$ & 1 & $1.3 \%$ \\
\hline Total & 77 & 38 & $49.4 \%$ & 34 & $44.2 \%$ & 5 & $6.4 \%$ \\
\hline
\end{tabular}


Table (5) : Immunostaining results and final diagnosis of the problematic cases:

\begin{tabular}{|l|l|l|l|l|}
\hline Initial diagnosis & No & Immuno-staining & Result & Final diagnosis \\
\hline $\begin{array}{l}\text { ?Papillary } \\
\text { carcinoma } \\
\text { ?? hyperplastic } \\
\text { nodules }\end{array}$ & 8 & $\begin{array}{l}\text { High Molecular weight keratin } \\
\text { \& S-100 }\end{array}$ & $\begin{array}{l}3 \text { cases both } \\
(+\mathrm{ve})\end{array}$ & $\begin{array}{l}\text { Papillary } \\
\text { carcinoma }\end{array}$ \\
\cline { 3 - 5 } & & $\begin{array}{l}5 \text { cases both } \\
(-\mathrm{ve})\end{array}$ & $\begin{array}{l}\text { Hyperplastic } \\
\text { Nodules }\end{array}$ \\
\hline $\begin{array}{l}\text { ?Follicular } \\
\text { carcinoma }\end{array}$ & 8 & Factor VIII & $3(+\mathrm{ve})$ & $\begin{array}{l}\text { Follicular } \\
\text { carcinoma }\end{array}$ \\
\cline { 3 - 5 } & & $5(-\mathrm{ve})$ & $\begin{array}{l}\text { Follicular } \\
\text { adenoma }\end{array}$ \\
\hline $\begin{array}{l}\text { ?Medullary } \\
\text { carcinoma }\end{array}$ & 2 & Chromogranin A & $(+\mathrm{ve})$ & $\begin{array}{l}\text { Medullary } \\
\text { carcinoma }\end{array}$ \\
\hline $\begin{array}{l}\text { ?Medullary } \\
\text { carcinoma } \\
\text { ?insular } \\
\text { carcinoma }\end{array}$ & 1 & Chromogranin A & $(-\mathrm{ve})$ & $\begin{array}{l}\text { Insular } \\
\text { carcinoma }\end{array}$ \\
\hline
\end{tabular}




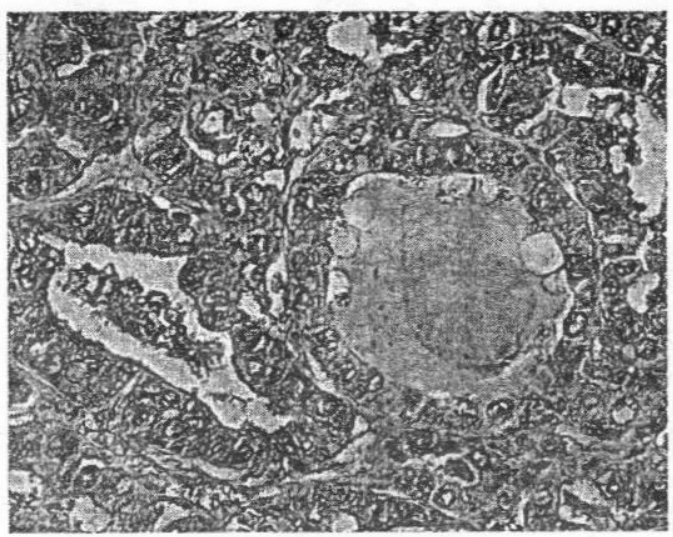

Fig. (1): Positive $S 100$ in papillary carcinoma (immunostain $\mathrm{x} 400$ )

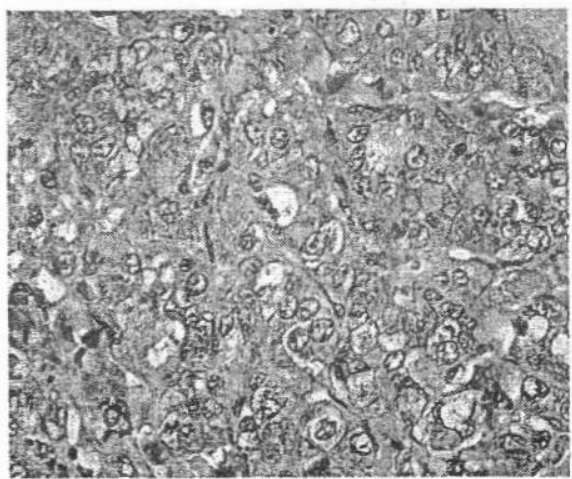

Fig. (2): Positive HMWK in papillary carcinoma (immunostain $\mathrm{x} 400)$.

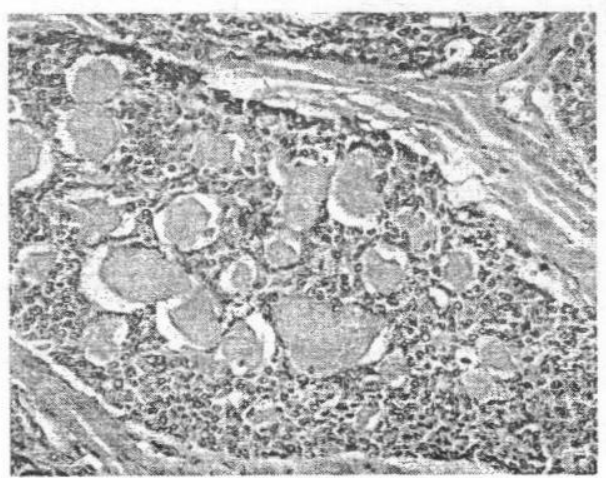

Fig. (3): Medullary carcinoma, follicular variant (x100). 


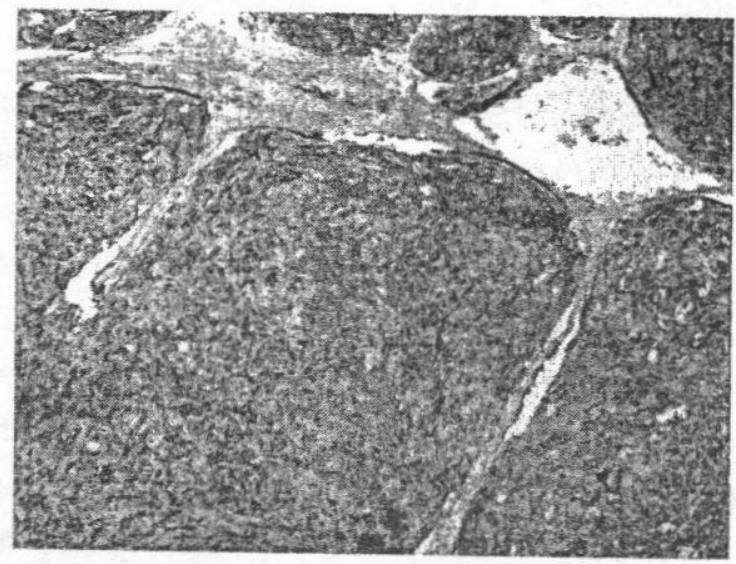

Fig. (4): Positive chromogranin in medullary carcinoma (immunostain $\times 100$ ).

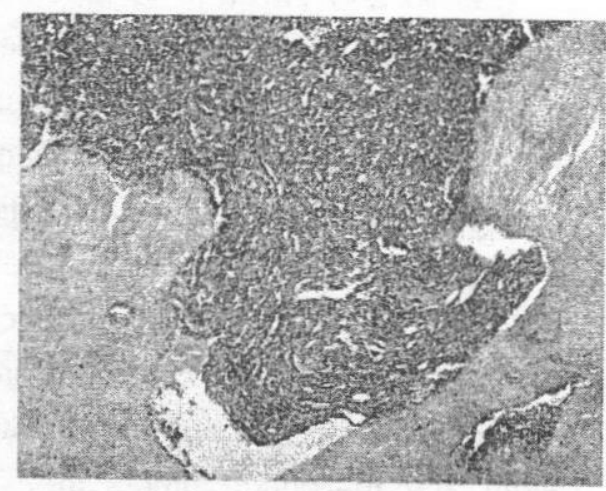

Fig. (5): Follicular carcinoma with mushroom shaped capsular invasion (x100).

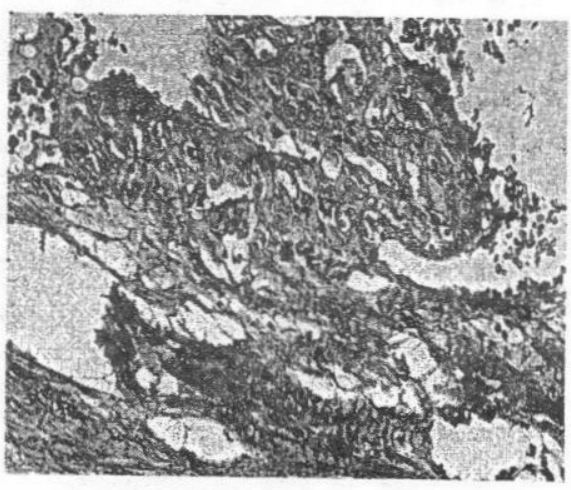

Fig. (6): Positive VIII in equivocal vascular invasion (immunostain $\mathrm{x} 200$ ) 


\section{DISCUSSION}

The problems involved in the histopathological interpretation of thyroid tumors with follicular pattern has been repeatedly alluded. The main problems seem to involve the distinctions between hyperplastic nodules, follicular adenoma, follicular carcinoma \& follicular variants of papillary and medullary carcinoma. Immunohistochemistry has been utilized in an attempt to resolve these issues.

The evaluation of solitary thyroid nodule is a common thyroid problem. The main goal in evaluating these nodules remains whether the detected nodule is malignant, especially in presence of any of the risk factors. They are found in $4 \% \wedge \mathrm{j} \%$ of adults by palpation and in $13 \% \mathrm{TV} ; \%$ when ultrasound detection is used. In autopsy studies, they have a prevalence of approximately $50 \%$.(2).

In our study, the solitary thyroid nodule represented $32 \%$ of all thyroidectomy specimens during the period of the study, since the specimen sample included only surgically removed glands, and because many of the cases that were diagnosed as solitary nodule on clinical and radiology level proved on pathologic examination to be a dominant nodule of multinodular gland. On the other hand, Namou and Lavertu(14), reported nodule prevalence as $49.5 \%$. They reported that the prevalence varies according to the method of screening used in different studies, but the true prevalence of thyroid nodules can be detected from pathologic examinations of thyroid glands at autopsy rather than from surgically excised specimens.

Namou and Lavertu(14), reported that excision biopsies give a higher yield of malignancy than needle aspirate since many of the cases diagnosed by aspirate as non neoplastic will be treated medically not surgically. They reported that the frequency of cancer in surgical specimens increased to $32.9 \%$. In agreement with them, the malignant tumors in this study showed a high incidence up to $28.57 \%$. This can be explained by the collection of cases of this study from the oncology center, which is considered as a referral center for neoplastic cases especially the malignant ones. 
As regard gender predilection, this study showed an overall female predominance; the female to male ratio was 2.5: 1 , which is in agreement with Hebra et al. and Mazzaferri (3 \&15), who reported that solitary thyroid nodules are 3-4 times more common in women than men.

Regarding the age of the patients, there was a wide range of age (15-80 years). This came in agreement to Mazzaferri (15).

Yeung and Serpell (2), reported that the commonest cause of nodule is the goiterous nodule, the commonest neoplastic lesion is follicular adenoma and the commonest malignancy is papillary carcinoma. In agreement with that, in this study the goiterous nodule was $(35.1 \%)$, follicular adenoma $(32.5 \%)$ and the commonest malignant neoplasm was papillary carcinoma (16.5\%).

Regarding atypical adenoma, Livolsi, et al. (16), stated that it is benign and regarded it as a variant of follicular adenoma. Welker and Orlov (17), also considered atypical adeno$\mathrm{ma}$ as benign but they mentioned it as a separate entity in their classification. Vasko et al. (18), on the other hand, suggested that atypical adenomas are a heterogeneous group, some are truly benign tumors and some are premalignant. In this study, atypical adenoma was considered as a benign neoplasm, but separated from follicular adenoma in terms of prognosis, post-operative therapy and value of follow up, as mentioned in the classification of (17).

Regarding Hy̌rthle cell tumors, Livolsi et al.(16), suggested that oncocytic tumors are treated like follicular tumors. DeLellis and Williams (19), also stated that completely oncocytic tumors are still regarded as a variant of follicular neoplasms, but it is important to identify them separately since they show different molecular features. In this study, Hžrthle cell tumors managed as follicular tumors in terms of capsular and vascular invasion and staging. They represented $2.6 \%$ of the malignant nodules, this was the same figure mentioned by Rosai et al. (20), they reported that Hyrthle cell carcinomas account for 2 to $3 \%$ of all thyroid carcinoma.

MANSOURA MEDICAL JOURNAL 
DeLellis and Williams (19), stated that the incidence of papillary carcinoma has increased world wide but the figures show great variability (5-35\%) depending on the area, sampling technique and the source of data; autopsy specimens show much higher rates than specimens from clinically apparent patients (caused by detection of many subclinical microcarcinomas). In our study, papillary carcinoma was also the commonest malignant tumor, and it represented $15.58 \%$ of the total.

Yamamoto et al.(10), reported that both clear and grooved nuclei are also reported in many benign thyroid lesions; however they were focal and do not stain for HMWK or S-100. In this study also, staining for HMWK or S-100 was useful; it was done to three cases with questionable nuclear clearing and inclusions \& were positive in the three cases, so they were considered papillary carcinomas.

DeLellis and Williams (19), reported that medullary carcinoma showed a variety of patterns, including follicular variant but with no clinical signifi- cance. In this study, there were two cases of medullary carcinoma with follicular pattern and were strongly and diffusely positive for chromogranin.

Regarding follicular carcinoma, Livolsi et al.(16), stated that it accounts for $10-15 \%$ of thyroid malignancies. In our study, it was $(5.19 \%)$ \& it was explained by the low number of cases.

\section{Conclusion :}

Most thyroid tumors are diagnosed by morphology alone. However, thyroid tumors with a follicular growth pattern could be sometimes a diagnostic challenge. Immunohistochemistry can be used for definitive diagnosis in case of unusual looking tumor. In this study, immunohistochemistry was used to confirm the diagnosis for all cases of medullary carcinoma with follicular pattern. Also it was used in detecting true vascular invasion in follicular carcinoma by using factor VIII. S-100 and HMWK were also very useful in nodules with questionable nuclear features of papillary carcinoma. 
REFERENCES

1. Rosai J. (2004) : Rosai and Ackerman's Surgical Pathology, 9th edn, vol 2, Mosby press pp: 515-94.

2. Yeung M J., Serpell J W. (2008) : Management of the Solitary Thyroid Nodule. The Oncologist; it represented $8.9 \%$ of the malignant tumors it represented $8.9 \%$ of the malignant tumors 13:105-112.

3. Hebra A., Miller M., Thomas PB. (2010) : Solitary thyroid nodule. eMedicine, Pediatrics, General medicine, Endocrinology.

\section{Luoto R.,Grenman S., Salonen} S., et al (2003) : Increased risk of thyroid cancer among women with hysterectomies .Am J Obstet Gynecol, 188:45-8.

5. Baloch Z.W. and Livolsi V.A. (2004) : Pathology of thyroid and parathyroid disease in: Mills S., Carter D., Greenson j.K et al Eds:
Sternberg's diagnostic surgical pathology, Vol 1, Lippincot Williams \&Wilkins Philadelphia Baltimore. New York, London, Bueneos Aires, Hong Kong, Sydney, Tokyo pp: 557-620.

6. Cooper DS, Doherty GM, Haugen BR et al (2006) : Management guidelines for patients with thyroid nodules and differentiated thyroid cancer. Thyroid; 16:109-142 .

\section{Stephenson T.J, Griffiths D.W.R., Mills P.M. (1986) : Com- parison of Ulex europaeus I lectin binding and factor VIII-related antigen as markers of vascular endo- thelium in follicular carcino- ma of the thyroid. Histopa- thology, 10: 251-2.60.}

8. Chan J.K.C. (2003) : Thyroid and parathyroid in: Weidner N., Cote RJ., Suster S., Weiss LM Eds: Modern Surgical Pathology, 1st edn, Vol 2. Elsevier Sience, Philadelphia, London, New York, St. MANSOURA MEDICAL JOURNAL 
Louis, Sydney, Tokyo:

Saunders pp: 1661-1754.

9. Furlan J.C., Bedard Y.C and Rosen I.B. (2004) : Clinicopathologic significance of histologic vascular invasion in papillary and follicular thyroid carcinomas.J Am Coll Surg, 198(3): 341-8.

10. Yamamoto Y., Izumi and Otsuka H. (1992): An immunohistochemical study of epithelial membrane antigen, cytokeratin, and vimentin in papillary thyroid carcinoma. Recognition of lethal and favorable prognostic types. Cancer, 70(9): 2326-33.

11. Arif S., Blanes A. \& Diaz-Cano S.J (2002) : Hashimoto's thyroiditis shares features with early papillary thyroid carcinoma. Histopathology, 41, 357-62.

12. Frates $M C$, Benson $C B$, Doubilet PM et al (2006) : Prevalence and distribution of carcinoma in patients with solitary and multiple thyroid nodules on sonography. $\mathrm{J}$ Clin Endocrinol Metab; 91: 3411-3417.

13. Welker M.J. and Orlov D. (2003) : Thyroid Nodules. Am Fam Physician, 67(3): 1016-9.

14. Namou K. and Lavertu P. (2003) : Evaluation of a thyroid nodule. Otolaryngol Clin North Am, 36(1): 1733.

15. Mazzaferri E.L. (1993) : Management of a solitary thyroid nodule. N Engl J Med, 328: 553-9.

16. Livolsi V, Baloch Z, Zubair, et al (2004): Follicular Neoplasms of the Thyroid: View, Biases, and Experiences. Advances in Anatomic Pathology. 11(6):27987.

17. Welker M.J. and Orlov D. (2003) : Thyroid Nodules. 
Am Fam Physician, 67(3): 1016-9.

18. Vasko V.V., Gaudart J., Allasia C., et al (2004) : Thyroid follicular adenomas may display features of follicular carcinoma and follicular variant of papillary carcinoma. Eur $J$ Endocrinol, 151 (6):779-86.

19. DeLellis R.A. and Williams E.D. (2004) : Thyroid and Parathyroid tumors. In: Ronald A. Delellis, Ricardo V. Liod,
Philipp V. Heitz., Charis Eng eds: World Health Organization Classification of tumors. Pathology and Genetics, Tumors of endocrine organs. IARC Press Lyon. pp: 49-133.

20. Rosai J., Carcangiu M.L., DeLellis R.A. (1992) : Tumors of the thyroid gland in: Rosai j., Sobin L.H Eds: Atlas of Tumor Pathology, 3rd Series, Fascicle 5. Washington D.C.: Armed Forces Institute of Pathology. 
